\title{
What do University Language Teachers Say About Language Teaching Research? ${ }^{1}$
}

\section{Desmond Allison and Julia Carey}

Although the relationship between research and language teaching is often discussed among applied linguists, the views of language teachers are often reported only anecdotally if at all. Our article explores how language teaching colleagues in a Canadian university view this relationship as expressed in open-ended questionnaire responses and contributions to follow-up discussions. We ask what research issues interest colleagues and how teaching insights might contribute to research. Responses proved remarkably full and frank, and our investigation elicited ideas for a collective effort to develop a shared program of language teaching research.

Alors que le rapport entre la recherche et l'enseignement des langues fait souvent l'objet de discussion en linguistique appliquée, le point de vue des enseignants de langue, dans la mesure où il est évoqué, est le plus souvent présenté comme information anecdotique. Notre article étudie la perception qu'ont les professeurs de langue, collègues dans une université canadienne, de ce rapport. Nos données reposent sur un questionnaire à questions libres et les discussions qui en ont découlé. Nous avons demandé aux professeurs quels sujets de recherche les intéressaient et dans quelle mesure ils croyaient que l'enseignement pouvait contribuer à la recherche. Les réponses ont été d'une exhaustivité et d'une franchise surprenantes. L'étude a élicité des idées relatives à un effort collectif visant un programme partagé de recherche en enseignement des langues.

\section{Introduction}

Our purposes in this article are twofold. As scholarly activity, we report on an investigative study for a readership of language teachers and languageteaching researchers, and relate our account to issues in professional literature. At the same time, our investigation is a form of professional action and a step toward a program for further action in our workplace. This dual agenda is fundamental to our research and is prominent in the article. It also poses an interesting dilemma for the status of our activity, which we take up in a postscript on research, action, and ethics.

Our question, What do language teachers say about language teaching research? is important for both teaching and research. The enquiry initially sounds quite straightforward. It relates to interests in teachers' attitudes and beliefs (Richards \& Lockhart, 1993; Woods, 1996) and to efforts to make 
teachers' voices more widely heard in the research literature (Bailey \& Nunan, 1996). Similar concerns for learners are just as important, but not our direct focus here. Work in this tradition pursues better understanding and more effective collaboration between the worlds of teaching and research, in teacher education and throughout professional life. We see these as valuable endeavors and seek to contribute to them.

The issues are, however, far from simple. The relationship between researchers and teachers has been a persistent concern in many professional discussions, including those we cite. In saying this, we do not just take for granted that researchers and teachers form distinct groups. Many individuals combine both roles: applied linguistic researchers often teach, some in second-language classes, and many second-language teachers carry out research activities, some reporting them in published forums. More radically, we might imagine a fusion of teaching and research roles in an autonomous investigative pedagogy and even a corresponding career structure. This could be an ultimate extension of the notion of teacher research (Edge \& Richards, 1993; Freeman, 1998; Hopkins, 1993; Nunan, 1989), or of reflective practice (McDonough \& McDonough, 1997; Schön, 1983). For our purposes, however, retaining a distinction between teachers and researchers and between teaching and research remains closer to most professional experience and helps to highlight issues of inequality that we cannot afford to ignore.

We outline two possible accounts of the relationship between second-language teaching and associated research. Our comments are selective and concise, as existing literature devotes much space to the views of applied linguists. The focus of our investigative study is on the views of language teachers.

One possible, worst-case model of the relationship between research and teaching in second-language classes would be to present it as essentially feudal. Tenured academics occupy positions of power and privilege, develop research agendas, farm out most of the associated work, and receive most of the proceeds. In contrast, language teachers labor in their classrooms along lines laid down for them by others and often put in extra effort to carry out supervised research studies in order to obtain higher qualifications in the hope that these may advance their own careers as well as those of their academic supervisors.

We believe (and hope) that research as feudalism is an inadequate model. Our sketch of associated work, for example, does not distinguish between two goals, teaching students and producing research findings, for which we could reasonably expect teachers' priorities and levels of ownership to differ. But the model does offer a pointed caricature of excessively hierarchical trends over the years in language-teaching and applied linguistics. Concerns over these trends are not lightly dismissed and recur in our data. 
Problems of inequality of power and status have long been discussed in second-language teaching and applied linguistics. At a 1986 conference on language teacher education in Hong Kong (Bickley, 1987), Bolitho (1987) observed:

As long as a hierarchical system is seen to operate, there will be those who make progress and those who don't. As long as applied linguists remain in universities and express themselves in terms which teachers find difficult to understand, but somehow feel they ought to understand, as long as the rules for professional advancement are devised by academics so that training takes place on their territory and on their terms, teachers will continue to feel inferior. As long as teaching continues to be regarded as a lower-order activity, involving high stress, large numbers of contact hours and low pay, and as long as those involved in theory have visibly less of the first two and considerably more of the last-mentioned commodity, there will be imbalance in the profession. (p. 30)

Changes effected in universities in many settings over the past two decades may have reduced some of the differentials that Bolitho's remarks evoke in terms of reported stress levels, working hours (though not contact hours), and probable extent of pay differences. However, it still generally remains the case that academic applied linguists earn more and teach less than second-language teachers. Most published commentary about this issue appears to accept that academic applied linguists, including teacher educators, occupy a different role from that of second-language teachers and that some imbalance in the profession or between the related professions is a fact of organized institutional life. Even taking this view, other elements in Bolitho's critique about the nature of professional training and of professional discussion remain very much to the purpose.

Other influential commentators such as Allwright (1993, 2003), Brumfit $(1987,1997)$, and Widdowson $(1987,1990,2000)$ have variously articulated the complexities of the relationship between research and language teaching practices (see comments in Allison, 2004). A common theme is the need to recognize and respect research and teaching as separate areas of expertise and the desire to work from there toward some form of partnership between teachers and researchers. Interestingly, such a partnership is something that Bolitho (1987) identifies as the only way to answer some of the key questions about classroom language-learning and teaching.

One issue for such a partnership is the need to derive authority from relevant knowledge (authoritative transactions) and not from hierarchical power relations (authoritarian interaction, Widdowson, 1987, 1990). Researchers and teachers each bring distinct but (we hope) relevant forms of knowledge to bear. Another issue is the ever-present danger that academic 
applied linguists, caught up in their own relatively privileged scholarly communities and roles, are likely to lose their second-language classroom know-how and sense of what is feasible unless they create ways to reengage with classroom teaching. Allwright (2003) pursues this concern further than most. Admitting that academic researchers have often pursued misguided agendas in the name of efficiency and improvement, he proposes that "trying to understand the quality of life in a given situation" (p. 120) is in itself a fundamental and valuable goal for what he and others term exploratory practice.

As an alternative to research as feudalism, research as partnership clearly serves our purpose as a more desirable model. At the same time, it can mean a number of things and can give rise to its own problems. We need to think about what each partner has to offer, and to gain (or lose), from such an association in any situation, not least our own. We also need to keep in view the possibilities for partnership between research and teaching roles in the life of the same individual and in the activities of a single professional group. Our plans for situated action to encourage partnership will also require critical reflection and open investigation.

\section{The Study}

This study elicits and examines comments of language teaching colleagues in a Canadian university about how they perceive the actual and possible relationship between their professional practice and language-teaching research. We first outline our situation as we viewed it when planning our study, indicate our research purposes, then introduce participants (including researchers), comment briefly on methods, and present findings from a preliminary content analysis. In closing, we comment on what we have learned so far, where we see this initiative heading, and why we think it matters. A postscript considers implications for ethical research policies and procedures in the humanities and social sciences.

\section{Situation and Purpose}

(Why do it? How does this research translate into useful action?)

The relevant university's School of Linguistics and Applied Language Studies (SLALS) is potentially an ideal environment for collaboration between theorists and practitioners. The School's activities include (with others) the design and teaching of undergraduate and graduate degree programs in applied language studies (ALS), an undergraduate program in general linguistics, a certificate in TESL, credit courses in EAP and in several other languages (specified below), and intensive courses in ESL. This rich diversity, however, can bring its own problems. As SLALS has become larger and more complex, individuals and groups have reported a keener sense of 
isolation and lack of connection with the work and ideas of others. Renewing or re-creating such connection is our aim for this study as on-site action. We are convinced that this goal also has wider professional relevance.

Some collaboration does continue in SLALS, but much of this has taken the form of intern observation or graduate research projects that use the classroom but may not contribute to it directly or substantially. Another form of connection between research interests and classroom concerns is through a speaker series, but this is something that teachers typically attend as audience rather than prime movers. In sounding these cautions, we recognize that efforts are continuing to address such concerns. We particularly welcome attempts to encourage dialogue with teachers who admit observers to their classes, to provide these teachers with useful feedback, and in some cases to involve them as co-investigators. Taylor et al. (2005) have reported at a TESL Canada symposium on this kind of collaborative research.

Serendipitous collaboration occurs through projects that are initiated to provide information for planning purposes. In these cases, groups of teachers may work together, and among them may be individuals who teach in both EAP and CTESL or linguistics and ALS courses. Valuable as such instances are, teacher involvement is still occasional. We would like to go further with colleagues and create a sustainable culture of collaboration and dialogue where theory and practice inform each other by design, not chance, and where teachers are generally encouraged to share, pursue, and enrich their ideas through discussion and investigation. We might describe this as a what if? community of practice.

To achieve this goal we need to understand why the obvious potential for working together seems at present to bear only random fruit. Are there barriers to collaboration that can be identified and removed? How far are we influenced by the broader relationship between the researcher and the teacher in the field of ALS? Are we hampered by attitudes or by practical constraints, or both? Informal exchanges in halls and offices still suggest at times that the hierarchical structure of the academy works much like feudalism, with the researchers at the top dispensing leisurely wisdom and the serfs laboring in the classroom, too exhausted to engage beyond daily survival. This model, or metaphor, is a point of departure that we would prefer to leave behind us. But we first wish to know how accurately it represents teachers' perceptions of the state of affairs in SLALS, and more generally in the profession. We then wish to ask, hear, suggest, and discuss how we might best work for a more democratic, horizontal relationship, one in which research and teaching are truly in partnership.

We therefore set out to discover how a group of language teacher- ESL, $\mathrm{EAP}$, and other languages-see the relationship between research and teaching and their own role as potential collaborators in SLALS. We are interested in their perceptions of barriers and constraints, but also wish to explore how 
to facilitate collaboration and communication so that the seeming gap between research and practice narrows. This local investigation relates to a more general question. Are ALS research and language teaching different places on a single continuum with fluid movement between positions, or are they distinctly different spheres that only occasionally intersect when the classroom can be of service to the researcher?

\section{Participants}

This study originated in discussions between us about the relationship between second-language teaching and research in professional life, our own careers, and our working situation. We identified research as feudalism as a useful parody of attitudes and of institutional arrangements that pose real dangers, and research as partnership as a goal that is far easier to declare than to achieve, but that we wished to pursue in our situation.

Our own roles are relevant as we are working with colleagues. One researcher came recently to Canada, to assume the role of director of SLALS and a tenured professorship. The other, an instructor on a term appointment, is the coordinator of the credit-bearing English as Second Language, academic (ESLA) courses at SLALS, which are an instance of teaching English for Academic Purposes (EAP). The provision of these courses enables students to begin their degree studies in a controlled fashion before meeting the normal entry requirement for English as a second language. (Fox, 2004, has a fuller account).

Besides the ESLA courses, second-language teaching at SLALS comprises noncredit intensive courses in ESL for students who do not yet qualify for ESLA and other credit-bearing courses in several more additional languages (currently including American Sign Language, German, Inuktitut, Italian, Japanese, Mandarin, Russian, and Spanish). We invited teachers of these SLALS courses to take part in this exploratory study. Invitations were transmitted through electronic distribution lists. As we anticipated replies only from individuals currently teaching, we estimated the number of potential respondents as 55. Of these, 22 teachers (40\%) completed and returned the questionnaire, and 17 (about 30\%) participated in subsequent exchanges (16 being interviewed, and one providing comments by e-mail). Most respondents were from ESLA and/or intensive ESL teaching backgrounds, whereas a few had other language-teaching experiences at SLALS.

It is worth noting that several language teachers and respondents are concurrently students, including students in CTESL and MA Applied Language Studies programs at SLALS, as well as doctoral students at other universities. Some others are earlier graduates from these same SLALS programs. This both enriches and complicates the set of relationships among varying professional groups in the School. 
Another group of SLALS teachers offering communication courses in disciplines and professions (principally at present to students of engineering) was not included in the investigation as these courses are not designed as second-language teaching. Three of these colleagues with interests and experience in EAP/ESL teaching kindly agreed to pilot the questionnaire instrument, and to advise on the wording of the letter of invitation and the informed consent form for the study.

\section{Methods}

Modes of enquiry had to be manageable for ourselves and participants during a busy semester (there is no other kind). Eventually, two modes were chosen: an open-ended questionnaire and a follow-up discussion. Participants could volunteer either for the questionnaire alone, in which case they might choose to remain anonymous, or for both the questionnaire and the follow-up discussion, which would necessarily entail revealing identities. Details of the invitation, questionnaire, and informed consent form are in the Appendices.

On the potential benefits of open-ended questionnaires despite known problems, see Allison (2002), Bell (1999), McDonough and McDonough (1997), and Nunan (1992). For a more pessimistic view, see Cohen and Manion (1994). On the possible role of interviewers as co-participants in discussion with interviewees, see Kvale (1996) and sources cited above. Our follow-up discussions, which took a number of forms (e-mail exchanges, corridor chats, live group discussions, and one individual interview), allowed us to elicit initial responses to themes we had identified from questionnaires and to pursue selected topics further with participating colleagues.

The questionnaire and follow-up discussions generated extensive data. This study reports a summary content analysis. Each of us initially took one set of questionnaire responses and after repeated readings, generated interpretive categories on the basis of frequently mentioned content issues. We then exchanged and discussed categories and questionnaire response sets, identified parameters for an initial account of the data, and used these as points of departure in the discussion phase. Content summaries of follow-up discussions were then generated from a combination of listening (most discussions were recorded, in all cases with permission) and reading (e-mail messages; our notes from spoken discussions).

An important methodological issue concerns validation of our accounts of the data. This involves two ongoing stages: interpretive discussion between us, and elicitation of feedback from research participants and colleagues. These choices reflect time constraints and priorities for an investigation that has been designed to explore issues, raise questions, and generate ideas and action. In this light, validation itself becomes provisional 
and continuing. We have not attempted a formal discourse analysis, but we have been through the data carefully and repeatedly in order to question, reshape, and elaborate our emerging account of content themes. One encouraging feature that we report below has been the remarkable levels of candor to which our questions often gave rise. If we have somehow misunderstood or misrepresented what colleagues have had to say, we are confident that they will find a way to tell us so. Finally, we make a virtue of necessity. We believe that this approach to content analysis and validation has brought us close to the spirit of the sort of teacher research that we would most like our activity to encourage.

\section{Findings and Discussion}

As stated, 22 teachers responded to the questionnaire, an estimated response rate of $40 \%$ overall. Allowing for uncertainty (one anonymous respondent), the approximate response rate by category is highest for ESLA instructors $(70 \%)$, lower for intensive ESL teachers (35\%), and lower again for instructors offering other languages (15\%). These varying levels of participation are already a (predictable) finding that carries some implications for our inhouse concerns; our study is also likely to have been identified most closely with English-language teaching and especially with ESLA.

Twenty-one identified respondents indicated willingness to be interviewed. Arranging times for interviews posed some problems in practice. Sixteen teachers were eventually interviewed: five groups of three, one individual. Both of us took part, except that (again for logistical reasons) one group interview was only with the second-named author. One other respondent sent comments by e-mail.

The summaries that follow represent our attempt to convey key themes and what was typically said about them. We encode quotes from questionnaire responses as [Q], from group discussions as [D], and from the e-mail response as [E]; non-verbatim reconstructions from our own notes of group discussions are coded [D-notes]. The act of interpreting content themes is one in which findings and discussion coalesce. At the end of this section, we reflect on the influence of the research process on participants and focus on what can be done. Our conclusion reviews the importance of our findings for both reflection and action.

\section{Not enough time}

As expected, most respondents mentioned the lack of time and the time-consuming demands of teaching that leave little space or energy for conducting systematic research or carrying a project to completion and publication. As teachers, their first priority was to meet students' immediate classroom needs, and any research yearnings had to give way to the teaching imperative. 
I was disappointed to find that the effort and time involved in preparing for and teaching my classes left me with little chance to devote to catching up on research. [Q]

Unfortunately, I have not been able to devote sufficient time to systematic research on the ESL/EAP issues about which I have been concerned. [Q]

the significant course load does not allow instructors enough time to engage in research regardless of their level of interest. [Q]

Lack of encouragement/incentive/active discouragement/status issues

A recurring theme was the sense that teachers needed some (usually) external motivator to move into research mode or to follow through on a specific project. The institutional pressure on professors to publish is seen as both an incentive and a stamp of approval. But research is not part of a language teacher's employment mandate. The desire for encouragement and recognition may speak to a certain insecurity and lack of confidence among the language teachers. But it is also symptomatic of the institutional hierarchy, evoking a kind of class system that urges teachers to know and keep to their place in the order of things: a view uncomfortably close to our original tongue-in-cheek characterization of the feudal metaphor.

original research opportunities are limited-this is most often because the nature of the position does not include research responsibilities. [Q]

I also wonder about motivation for those colleagues in language teacher and instructor positions, since the descriptors for these positions focus on teaching, not research. [E]

there's no reason to do it (research) because it's not going to bring anything to us at all-there will be no reward whatsoever-probably no recognition. [D]

have to be self-motivating-put yourself forward when calls for papers go out. [D]

Our questions aroused strong responses from some teachers; we had apparently unleashed pent-up frustrations about institutional constraints and issues of status. We might say that the questions and answers passed through the filter of departmental history, acquiring a nuance we had not necessarily intended. The surprise was how many teachers believed that the department and the university actively discouraged research because language teachers should not presume to be like professors or because research was not written into the union contract for language teachers. Occasional comments extended this sense of discouragement and constraint beyond the immediate local setting into the profession as a whole. 
David Nunan whom we'd always really admired gave a talk and he said: If there are any teachers here ... if you're thinking about doing research-basically don't. Really in shock-came back very, very upset. [D] [See our comments below and footnote for David Nunan's own take on this.]

I've been told several times ... high ranking members of the university have actually said explicitly-the university does not want language teachers acting like professors and publishing research. [D]

I felt differently when I was doing my master's-people definitely treated me differently. [D]

there IS a hierarchy in terms of who is or is not listened to and read. [from D-notes]

we have different strata here-when I cease to be a student still not faculty-so don't have the same status as faculty members. [D-notes]

Lack of expertise

Some of the teachers we interviewed lacked confidence in their research methodology and fitness to complete projects without mentoring or supervision from an expert. There was a reluctance to strike out alone even among master's graduates. They felt competent to handle literature reviews, but not to manage primary research. Deficiencies in research design, statistical analysis, and in negotiating the process of publication were directly mentioned or obliquely touched on. Those teachers either currently taking courses or recent graduates of courses generally felt in closer touch with a community of practice that would be a source of support and expertise. But here too the expert/novice distinction persisted, and it was to their graduate teachers that individuals instinctively turned.

don't know enough to figure out what to do, even after doing MA ...

missing steps to follow ... don't have competence to set it up. [D-notes]

need someone to help formulate questions, or talk through ideas (theme in at least two discussions. [D-notes]

someone who's done a fair amount of research and had it published in a refereed journal—someone who's gone through the struggle

themselves. [D]

Am I a real researcher? Is this/that real research?

Ambivalent best describes how our respondents see themselves as researchers and how they present their own research ideas. We see a continuum or spectrum from informal, anecdotal, not "real" research done by teachers as part of reflective teaching, to formal, objective, "real" research done by 
professors using the classroom as a data source. The former feeds into daily teaching practice, but remains in that loop, whereas the latter is published in the research community and may or may not have practical teaching applications. Attitudes to the "expert" researcher also span a similar continuum. On the one hand, we find evocations of low status captured in phrases like "a mere language teacher," and at the other extreme "a certain contempt" for researchers who are not only removed from the reality of the classroom, but make claims based on flawed methodology. In the middle ground we find some optimism that the two roles are interchangeable.

So, do I see myself as a researcher in relation to my teaching? Not an active one, but a potential one (let's hope!). [Q]

The research I do whilst teaching is not formal but rather ad hoc.

However, I do think of myself as a teacher-researcher rather than only a teacher. [Q]

I feel that teachers are a different and distinct group from researchers, and they shouldn't be. Now it's them in their world and me in mine. [Q]

Research (published) and my own informs my teaching. Also my teaching informs my research. [Q]

I don't necessarily see it (feedback) as research, although I know many people do-a lot of anecdotal research. I see research as much more structured, demanding. [D]

What might teachers want to investigate/What do teachers investigate? Despite ambivalence over roles and status and concerns over time, many of our colleagues had ideas about teaching and learning that they wished to pursue, and in a number of cases were already pursuing. These teachers proposed a variety of research topics and questions, either as actual or as desirable instances of classroom-oriented investigations, including the examples that follow. Some of these involved research studies as part of work toward a teaching certificate or a graduate degree, but there were also several other instances of action research or reflective enquiry undertaken in the course of teaching.

- Electronic communication style;

- Computer use and writing;

- Placement testing and student attitudes;

- Benchmark development;

- Feedback;

- Influence of attitudes, experiences, and methodology on language learning;

- Fossilization-grammar;

- Oral assessment; 
- Belief systems and teaching choices.

The importance of asking questions about one's teaching and one's students' learning as an integral part of professional activity also came through in these discussions. As one teacher commented,

Keeping yourself happy as a teacher is very important ... keeping yourself going ... be happy and enthusiastic and communicate that to students ... find it difficult to go on and on and not see the end of the tunnel. [D]

Influence of research on participants

An important motivator for this research was the wish to give greater recognition and support to the kinds of teacher initiatives that surfaced from time to time during conversations with colleagues and to encourage better communication and fuller investigative exploration of ideas. As our study proceeded, it became clear that a hidden vein of research was waiting for an appropriate way to become visible. Words like visible, sharing, or making it public permeate responses from almost all the teachers we interviewed. For many of them, the act of communicating to others transformed reflective classroom teaching into exploratory research. This recurring motif signals a strong desire to have a legitimate voice not only in SLALS, but in the wider context of applied language studies.

Eliciting teachers' thoughts and feelings on these issues has already stimulated awareness and expectations, as has been evident in some responses and post-interview comments. It has also highlighted high levels of ambivalence, and in some cases skepticism, and has perhaps begun to help all parties understand the issues better.

Some comments appear still to assume and even seek an essentially hierarchical relationship between the neophyte wannabe teacher-researcher and the initiated researcher-professor. This is a hard paradigm to shake in spite of other perceived shortcomings of fealty to a feudal lord or lady. It may also have some validity if we view research as a form of apprenticeship, with the newcomer gradually acquiring membership of the guild of researchers through working alongside a more experienced practitioner. The key seems to be respect, and recognition that both expert and novice make a legitimate and valuable contribution to a project.

The ambivalence we found in many of the replies, spanning more than one question, seems characteristic of anyone moving from one relatively secure community of practice to another. Concerns about the rules of the new game, what will ensure acceptance or rejection, how to conduct oneself, and how to find a reliable guide are issues that our students face each time they enter a new classroom. Comparably perhaps, in being research-minded as teachers, we not only enrich our classroom practice, but place ourselves at 
that precarious but exciting intersection between the known and the unknown that can bring us closer to a student perspective.

In this study, we have seen our act of enquiry set in motion conversations that have begun to express and sometimes reshape how individuals view their own research. The number of projects in contemplation or in progress confirms that teachers are researchers even if they are wary of claiming their title to this sometimes-promised land. The beginnings of an in-house response to this situation is outlined below.

Can we at this point safely replace an essentially feudal scenario by one of partnership between language teachers and academic researchers? The original, bipolar image of a system designed to keep teachers in a subordinate position, working the land but not owning it, is not entirely dispelled by the responses we received. There is still unrest and underlying resentment of a hierarchy that restricts access to the rewards of "real" research. But this is balanced by groups of teachers banding together to claim some territory for themselves. The degree to which individuals are prepared to do this varies, as does the need for a leader of some kind to show the way and motivate others to follow. Perhaps the final feudal image to evoke is that of the barons demanding Magna Carta, but that particular partnership was won more by force than persuasion and still excluded the serfs. All told, we choose now to leave the feudal metaphor behind us and to work for genuinely inclusive forms of partnership that will extend to learners as well as teachers and researchers.

We had not anticipated the degree of frankness and passion that some of the questions set free. The teachers used the questionnaire, and especially the group interviews, to raise issues and express feelings and opinions that might have remained semi-silent murmurings in hallways and private conversations. It may be that this was an opportunity for teachers to speak openly to the new Director, who is one of the researchers. We had initially wondered whether this status might prove a barrier to communication-in fact it seemed to be a stimulus.

Finally, one participant observed during a group discussion that the research process itself is remembered and can influence later decisions and attitudes. We hope this will be both true and positive in this case as it already seems to be for ourselves.

What can be done?

Part of what we need to do is to make existing discussions, thoughts, initiatives, and investigations more visible, both to give them greater recognition and to encourage further growth. Through our focus group interviews, we now have a plan that will help us create this visibility. The idea is to combine the notions of an advisory research committee and an in-house publication forum. 
The forum will provide scope for teachers to share and report on projects at each stage of the development process. It will incorporate features of an on-line discussion board, a teaching exchange, and an in-house journal. One section-provisionally named Inklings-initiates what-if thoughts that may grow into projects as colleagues engage with an idea. The teaching exchange is an opportunity to share materials and methodology. Another planned section reports on projects in progress. These sections will feature ongoing contributions throughout the year and be a way to communicate and stimulate research-minded thinking and conversations among the language teachers. A final, once-or-twice-a-year section will present completed work that has been read by the advisory research committee and deemed ready for in-house publication. This is the final stage of revision in a supportive environment before submitting the paper to an external publication.

Questions of implementation and sustainability remain to be fully worked out, but the willingness is there. We hope this process will offer the opportunities and encouragement that our respondents so evidently want and need to feel part of a legitimate research community that recognizes and values their contribution to SLALS and the field of ALS.

\section{Conclusion}

Many findings have been consistent with our initial expectations and other comments in related literature (McDonough \& McDonough, 1997). These center around the complexity and ambivalence of research for language teachers. There were often doubts, and sometimes apparently contradictions, over whether individuals saw themselves as researchers as well as teachers and whether research was encouraged. There were clear references to continuing academic hierarchy, often as a negative constraint, but sometimes also as a desired source of expert guidance and direction.

What most struck us were two features: the degree of frankness and passion in the replies (see above section), and the degree to which ambivalence over a research role for teachers extends to whether the perceived constraints are internal or external. Lack of time for research, for example, was often attributed to externals in the form of heavy workloads and lack of release from teaching, but was sometimes attributed to internal, individual weaknesses in time management over an academic year. Many responses interestingly blended lack of time, lack of institutional status and active support, and lack of confidence in one's own expertise, or may have started in one of these areas but shaded into another.

Operationally, this blending of comments rendered our categorization of selected comments difficult and at times arbitrary and suggested extensive cross-referencing in data compilation (e.g., between lack of time and lack of support). Interpretively, the ambivalence and complexity were most instructive. Lack of confidence arises within a social setting and may be individually 
internalized as a response to things said or done (or not said and done) by others, sometimes years earlier. Conversely, what individuals hear being said and done may be filtered and even perhaps distorted through prior expectations. We had many examples in our data of cases where in our perception teachers had heard what they feared to be the case, not what they hoped. $^{2}$

Many views and uncertainties remain throughout applied language studies (and other fields) over what may or should count as research. We would like to suggest, and did so in at least one group discussion, that what McDonough and McDonough (1997) term the "minimalist view of a 'research stance'" (p. 7) is of more value than extended debate over the is-thisreally-research? status of particular activities or products. A research stance implies processes of question-raising, planned investigation, and willingness to rethink assumptions in the light of evidence. All of these were apparent in colleagues' comments and searches for greater understanding of students and classroom events. Research-mindedness of this kind is, in our view, an inseparable part of professionalism in language teaching. It is also an obvious and invaluable resource for research activity in applied language studies.

A research stance also allows for varied levels of engagement at various times. If we construct a continuum between active research, awareness of present or past research, and lack of direct involvement in research, we would see this line as one along which each of us can move according to the nature of each activity and our degree of interest and involvement in it, and not as one on which various individuals and hierarchical groups occupy single points as fixed territory (as active researcher, consumer of research, recollector of past research, or person no longer involved with research). The aim is then to encourage movement along this line in either direction according to varying stakes in varying activities, leading to variation in roles for all parties as a basis for both community and partnership. ${ }^{3}$

Translating this aspiration into action remains the challenge. We outline some concrete suggestions that we intend to pursue, but the hardest part will continue to involve communication. Part of the message has to be that research expertise does not take us beyond uncertainty (which sometimes frustrates seekers of definitive answers), but probably does equip us to deal with uncertainty in informed ways. Part is that we are all learners. We were surprised to identify the extent of apparent dependence on expert guidance or control among language teachers, who are often advocates of developing learner autonomy, but we probably should not have been. Much current literature supports an account of learner autonomy as emergent and as socially constructed (see review in Huang, 2003). This has to apply also to the autonomy of teachers as researchers in and around their own classrooms. In addition (as a critical remark from one reviewer has pertinently reminded 
us), most prevailing discourses still take for granted that it is academics, not classroom teachers, who drive research agendas: a formulation that emphasizes dichotomy over role continuum and dependence over partnership contrary to the kinds of relationship and emergent autonomy that we are working toward here. Our task now is to renew and extend forms of communication and communal action that encourage language teachers to develop and exercise a research stance in the course of their work.

\section{Postscript: Research, Action, and Ethics}

The dual nature of this investigation as research and as action has posed an interesting dilemma for us, and more particularly for the university's committee on research ethics. From one possible perspective on research, the in-house setting and the institutionally involved nature of our study could be seen as problematic because of the multiple interests of researchers and participants. In consequence, one initial suggestion we received from the university's research ethics committee was to consider conducting this study elsewhere.

We quickly pointed out that such a change would defeat the essential in-house developmental nature of our proposed activity and that we were not undertaking research for its own sake or primarily to contribute to generalizable knowledge. A revised assessment was that our study, even though we planned to present and publish its findings, remains by nature a form of institutional action to ensure quality control, in our case to seek better ways for SLALS to support teachers who might wish to adopt an investigative stance in their teaching situation. Given also that we were not carrying out research on students (as such, the concurrent student status of some language teachers in our study was incidental), it was determined that our activity did not require formal ethics clearance. We are glad to add that committee members had already commented favorably on our provisions for informed consent, possibly anonymous participation of colleagues, and right of withdrawal.

More generally, it seems that existing legislation and institutional practices concerning research ethics continue to face problems in responding appropriately to all forms of socially engaged research (including action research and teacher research) that are not designed to be detached from the settings and behavior that the enquiry seeks to illuminate. Fox, Artemeva, Darville, and Woods (2006) discuss these issues in some detail. Here too, space for research as appropriate action must be continually interpreted and negotiated.

\section{Notes}

${ }^{1}$ A version of this article was presented at TESL Canada, Ottawa, 2005.

${ }^{2}$ One instance may have been a colleague's account of what a group of teachers understood David Nunan to have said at a conference years ago, apparently in order to dissuade teachers 
from becoming involved in research. David Nunan's recent e-mail response to our enquiry assures us of his longstanding and continuing commitment to teacher research. He guesses that whatever he may have said was likely to have been a tongue-in-cheek comment to catch audience attention. This would be quite consistent with Nunan's lecturing style (from repeated observations by Allison). If this was so in the reported instance, the call to attention seems to have worked all too well, but not as the speaker would have intended.

${ }^{3}$ A line only provides for movement along a single dimension. A more elaborate metaphor might be that of a courtly dance, in which participants alternately approach and then draw back, positions themselves also alternate, and all these repeated movements convey mutual regard and respect.

\section{Acknowledgments}

We are extremely grateful to all participating colleagues: Selina Bishop, Emese Bukor, Larry Chalk, George Chouchani, Renata de Pourbaix, Peggy Hartwick, Eriko Hoshino, Margaret Kersten, Linda Librande, Marlene Lundy, Catherine NacNeil, Trudy O'Brien, Stephanie Pinnacle, Roxanne Ross, Eve Schnitzer, Jaffer Sheyholislami, Louise Smith, Adrienne Storey, Stephanie Tews, Cara Vandale, Carolyn Wood, and an anonymous respondent. Our thanks and appreciation go also to Kim Davis, Lisa Meyer, and Helen Triantafellou for their constructive feedback on the draft questionnaire and related materials.

\section{The Authors}

Desmond Allison is a professor and Director of the School of Linguistics and Applied Language Studies, Carleton University. He has published extensively on aspects of applied linguistics and English for academic purposes.

Julia Carey is an EAP coordinator and instructor in the School of Linguistics and Applied Language Studies, Carleton University. Her long career spans both L1 and L2 academic English and writing programs.

\section{References}

Allison, D. (2002). Approaching English language research. Singapore: Singapore University Press.

Allison, D. (2004). Changing understandings of classroom practices. Electronic Journal of Foreign Language Teaching, 1(1), 5-13. Available: http:/ / e-flt.nus.edu.sg

Allwright, R. (1993). Integrating "research" and "pedagogy": Appropriate criteria and practical possibilities. In J. Edge \& K. Richards (Eds.), Teachers develop teachers research (pp. 125-135). London: Heinemann

Allwright, R. (2003). Exploratory practice: Rethinking practitioner research in language teaching. Language Teaching Research, 7(2), 113-141.

Bailey, K., \& Nunan, D. (Eds.). (1996). Voices from the language classroom. Cambridge, UK: Cambridge University Press.

Bell, J. (1999). Doing your research project: A guide for first-time researchers in education and social science (3rd ed.). Milton Keynes, UK: Open University Press.

Bickley, V. (Ed.). (1987). Re-exploring CELT: Continuing education for language teachers. Hong Kong: Education Department.

Bolitho, R. (1987). Teaching, teacher training and applied linguistics. In V. Bickley (Ed.), Re-exploring CELT: Continuing education for language teachers (pp. 26-32). Hong Kong: Education Department.

Brumfit, C. (1987). A "whole profession" model of continuing teacher education. In V. Bickley (Ed.), Re-exploring CELT: Continuing education for language teachers (pp. 12-19). Hong Kong: Education Department.

Brumfit, C. (1997). Theoretical practice: Applied linguistics as pure and practical science. AILA Review, 12, 19-30. 
Cohen, L., \& Manion, L. (1994). Research methods in education (4th ed.). London, New York: Routledge.

Edge, J., \& Richards, K. (Eds.). (1993). Teachers develop teachers research. London: Heinemann

Fox, J. (2004). Test decisions over time: Tracking validity. Language Testing, 21(4), 437-465.

Fox, J., Artemeva, N., Darville, R., \& Woods, D. (2006). Juggling through hoops: Implementing ethics policy in applied language studies. Journal of Academic Ethics, 4, 1-4, 77-99.

Freeman, D. (1998). Doing teacher research: From inquiry to understanding. Pacific Grove, CA: Heinle and Heinle.

Hopkins, D. (1993). A teacher's guide to classroom research (2nd ed.). Milton Keynes, UK; Philadelphia, PA: Open University Press.

Huang, J. (2003). Coming to terms with difficulties and constraints: A classroom-based investigation of EFL learning in a Chinese university. Unpublished master's thesis, National University of Singapore.

Kvale, S. (1996). InterViews: An introduction to qualitative research interviewing. Thousand Oaks, CA: Sage.

McDonough, J., \& McDonough, S. (1997). Research methods for English language teachers. London: Arnold.

Nunan, D. (1989). The teacher as researcher. In C. Brumfit \& R. Mitchell (Eds.), Research in the language classroom (pp. 16-32). London: Modern English Publications (in association with the British Council).

Nunan, D. (1992). Research methods in language learning. Cambridge, UK: Cambridge University Press.

Richards, J.C., \& Lockhart, C. (1993). Reflective teaching in second language classrooms. Cambridge, UK: Cambridge University Press.

Schön, D.A. (1983). The reflective practitioner: How professionals think in action. New York: Basic Books.

Taylor, V., Woods, D., Barker, M., Carey, J., de Pourbaix, R., Doe, C., Girvan, A., Hartwick, P. Kanani, N., Nasif, A., Richel, K., Ross, R., \& Smith, L. (2005, May). Exploring teaching, collaborative classroom research and language learning: Issues and results. Paper presented at the Research Symposium, TESL Canada, Ottawa.

Widdowson, H.G. (1987). The pragmatics of language teacher education. In V. Bickley (Ed.), Re-exploring CELT: Continuing education for language teachers (pp. 4-11). Hong Kong: Education Department.

Widdowson, H.G. (1990). Aspects of language teaching. Oxford, UK: Oxford University Press.

Widdowson, H.G. (2000). On the limitations of linguistics applied. Applied Linguistics, 21(1), 3-25.

Woods, D. (1996). Teacher cognition in language teaching: Beliefs, decision-making, and classroom practice. Cambridge, UK: Cambridge University Press.

\section{Appendix A \\ Letter of Invitation (original also gave title of this paper)}

We would like to invite you to participate in a research study we are undertaking. If you agree to take part, this could involve either (a) completion of a questionnaire only, or (b) completion of a questionnaire and participation in a follow-up discussion.

Time needed: We estimate that composing reflective answers to the questions in the questionnaire might take about 20-30 minutes in all, perhaps less as the topics are likely to be familiar. Follow-up discussion could be either individual (with one or both of us) or in small groups, again for about 20-30 minutes, or might take the form of an e-mail dialogue, according to preferences. 
Potential benefits: The issues we are exploring are likely to be of professional interest, both generally and in the immediate workplace setting. The exchange of ideas could also contribute to the development of a shared program of language teaching research. We see this study as aiming to contribute to professional development of all participants (including the researchers) by fostering professional dialogue.

Potential risks: We do not anticipate any serious risks to participants. If colleagues are uncomfortable about expressing their views, either to the researchers or to others in follow-up discussions, they can opt to remain anonymous (or, of course, not to participate), without detriment. There are no "right" or "approved" answers to the questions we are asking. Participants will choose whether to respond openly (by replying to our e-mail) or anonymously (by completing a hard copy and not identifying themselves). Voluntary participation in a follow-up discussion cannot, of course, be anonymous. Participants have the right to withdraw from the research at any time. Participants' responses from either stage of the study will be cited anonymously if at all, unless participants specify that they wish to be identified when their words are cited.

Plans for dissemination: We intend to report on this study at TESL Canada in May 2005 , and if possible to publish a written version of that paper.

[Also names and signatures of the researchers]

\section{Appendix B \\ Informed consent form for questionnaire and possible follow-up discussion. (Original added space for name and signature where applicable)}

The purpose of this questionnaire is to elicit both experiential and attitudinal data from respondents, focusing on the relationship between research and practice in teaching.

If you agree to become a respondent, you have the option to return by email or anonymously in hard copy form.

If you choose to identify yourself, please send your responses by e-mail, and please also complete and return a signed copy of this sheet to one of us in the internal mail.

If you choose to remain anonymous, please print one copy of the questionnaire, complete it, and return it to one of us in the internal mail. Please do this only if you agree to allow us to cite your responses in the course of future research reports (written or spoken). If you do not agree to this, please don't complete the questionnaire.

For participants choosing to identify themselves: please complete all items that apply to you, then print and sign your name. Please choose one option for each item by checking the appropriate box. If you make any corrections, please sign them clearly.

1. [ ] I grant my permission to the researchers to cite my responses in reports of this research, whether spoken or written, as set out in item 2 below. 
[ ] I do not grant my permission to the researchers to cite my responses in reports of this research, whether spoken or written, as set out in item 2 below.

2. (If granting permission to cite)

[ ] Any use of my words in reports of this research should be anonymous.

[ ] Any use of my words in reports of this research should be attributed to me by name.

3. (If granting permission to cite)

[ ] Any use of my words in reports of this research is to be cleared with me in advance.

[ ] Any use of my words in reports of this research does not need to be cleared with me in advance.

4. [ ] I am willing take part in a follow-up discussion.

[ ] I am not willing to take part in a follow-up discussion.

5. (If willing to take part in discussion) I choose to take part:

[] individually

[ ] in a small group.

(Note: Small group participation would be face to face. Individual participation would be either face to face or through e-mail exchange, according to choice. Exact arrangements will be negotiated later.)

Other comments if any:

\section{Appendix C Questionnaire}

We want you to express your views. If a question limits your response, please comment and respond as seems best to convey your position. Please attach an extra sheet if necessary. Thank you for your time and comments.

1. Approximately how long have you been teaching?

Less than 5 years

5 to 10 years

10 to 15 years

15 to 20 years

More than 20 years

2. During your teaching career, which of the following programs have you taught?

ESL

EAP

ESP

Languages other than English

Comments, if any: (e.g., levels taught) 
3. Which of the following best describes the place of research findings and specific theories in your teaching?

A systematic influence

A regular source of ideas

An occasional source of ideas

Not a significant influence

Comments, if any:

4. How do you usually access or find out about relevant research? (Check all relevant boxes)

Professional journal subscription

Browsing on-line

From colleagues

Library books/on-line journals

Resource Centre

Other

5. How far and in what ways do you see yourself as a researcher in relation to your teaching?

6. We are interested in your views about research and teaching within the field of applied language studies. How would you describe the relative status of research and practice within the field?

7. In your view who sets the agenda for research? What are some of the consequences?

8. What do you see as the relationship between teaching and research both actually and ideally? 